\title{
Messenger RNA
}

National Cancer Institute

\section{Source}

National Cancer Institute. Messenger RNA. NCI Thesaurus. Code C813.

A class of RNA molecule containing protein-coding information in its nucleotide sequence

that can be translated into the amino acid sequence of a protein. 